\title{
Analysis of cellulose microfibril angle using a linear mixed model in Pinus taeda clones
}

\author{
Fikret Isik, Marcia Gumpertz, Bailian Li, Barry Goldfarb, and Xuan Sun
}

\begin{abstract}
Variation in microfibril angle (MFA) (degrees) among loblolly pine (Pinus taeda L.) full-sib families and clones was investigated using 43 clones from nine full-sib crosses tested at two locations. When the experiments were 12 years old, a total of 316 trees were drilled and $12 \mathrm{~mm}$ thick wood increment cores were collected. MFA for each growth ring in the wood core was measured using the SilviScan-2 tool. A quadratic mixed model was fitted to evaluate the MFA variation over different rings. Among the error covariance structures tested in the model, autoregressive order 1 was the best model for producing MFA estimates with the smallest errors. Estimated MFA was about $33^{\circ}$ in the pith (ring 1) of the trees and decreased to $18^{\circ}$ in the outer wood (ring 11). Full-sib crosses and clones within crosses explained about $12.5 \%$ of the total phenotypic variation. Repeatability of full-sib family means $\left(H_{\mathrm{f}}^{2}=0.46\right)$ was moderate but repeatability of clone means was high $\left(H^{2}{ }_{c}=0.79\right)$. Although it is possible to improve (decrease) MFA with recurrent selection in tree improvement programs to improve lumber quality, cost efficient and rapid methods for measuring MFA are needed.
\end{abstract}

\begin{abstract}
Résumé : Les auteurs ont examiné la variation de l'angle des microfibrilles (AMF) (degrés) parmi des familles de descendance biparentale et des clones de pin à encens (Pinus taeda L.). Pour ce faire, 43 clones provenant de neuf croisements biparentaux ont été testés à deux endroits. Au moment où les expériences ont atteint l'âge de 12 ans, des carottes de bois d'une épaisseur de $12 \mathrm{~mm}$ ont été prélevées sur un total de 316 arbres. L'AMF de chacun des cernes annuels contenus dans les carottes de bois a été mesurée au moyen de l'outil SilviScan-2. Un modèle quadratique mixte a été appliqué afin d'évaluer la variation de l'AMF entre différents cernes annuels. Parmi les structures de covariance de l'erreur qui ont été testées dans le modèle, la structure autorégressive d'ordre 1 était la meilleure car elle générait les prédictions de l'AMF avec les erreurs les plus faibles. L'AMF prédite par le modèle était d'environ $33^{\circ}$ près de la moelle (cerne 1 ) et diminuait à $18^{\circ}$ dans le bois situé plus près de l'écorce (cerne 11). Les effets dus aux croisements biparentaux et aux clones parmi les croisements expliquaient approximativement $12,5 \%$ de la variation phénotypique totale. La répétabilité des moyennes des familles de descendance biparentale $\left(H_{\mathrm{f}}^{2}=0,46\right)$ était modérée mais la répétabilité des moyennes des clones $\left(H^{2}{ }_{\mathrm{c}}=0,79\right)$ était élevée. Malgré le fait qu'il soit possible d'améliorer (réduire) l'AMF par la sélection récurrente dans des programmes d'amélioration des arbres pour augmenter la qualité du bois, des méthodes rapides et rentables sont nécessaires pour mesurer l'AMF.
\end{abstract}

[Traduit par la Rédaction]

\section{Introduction}

The cell walls of plants are composed of small cellulose structural units called microfibrils (Zobel and van Buijtenen 1989). Microfibril angle (MFA) (degrees) is the angle between the cellulose fibrils and cell longitudinal axis in the S2 layer of cell walls (Megraw 1985; Lichtenegger et al. 1999). The orientation of the cellulose fibrils in trees has a significant influence on paper properties (Entwistle et al. 2005); high MFA decreases the tear strength and stretch of paper (Uprichard et al. 1994). Strong relationships between MFAs and mechanical wood properties have been reported,

Received 17 July 2007. Accepted 20 December 2007. Published on the NRC Research Press Web site at cjfr.nrc.ca on 28 May 2008.

F. Isik, ${ }^{1}$ B. Li, and B. Goldfarb. Department of Forestry and Environmental Resources, North Carolina State University, Campus Box 8002, Raleigh, NC 27695-8002, USA.

M. Gumpertz. Office for Diversity and African American Affairs, North Carolina State University, Campus Box 7527, Raleigh, NC 27695-7527, USA.

X. Sun. 102 Seagroves Court, Apex, NC 27502, USA.

${ }^{1}$ Corresponding author (e-mail: Fikret_Isik@ncsu.edu). with lower MFAs associated with a desirable effect on lumber strength, stiffness, and dimensional stability (Cave and Walker 1994). MFA has a strong relationship with specific gravity and shrinkage of wood (Megraw 1985). Myszewski et al. (2004) did not find significant correlations between MFA and specific gravity. This may be due to a nonlinear relationship between two traits at mature ages of trees (Jordan et al. 2005). The MFA, along with specific gravity, is considered the most important indicator of wood quality for the forest industry (Jordan et al. 2005).

With advancement in tree improvement programs and intensive silvicultural regimes, rotation age of managed pine plantations has been drastically reduced. Wood produced from young plantations is called juvenile wood and has undesirable characteristics, such as lower density and low cellulose yield (Zobel and van Buijtenen 1989). Thus, tree breeders are giving more attention to genetic improvement of wood quality. Despite the importance of MFA on wood properties and on the end wood products, this trait has not been incorporated into loblolly pine (Pinus taeda L.) improvement programs, primarily because it is expensive and time-consuming to measure (e.g., using X-ray diffraction). Development of new instruments, such as SilviScan, provides new opportunities to scan trees for MFA (Evans and Ilic 2001). 
Considerable genetic variation in MFA was reported in Pinus radiata D. Don (Kumar et al. 2006), Picea abies (L.) Karst. (Lundgren 2004), and Eucalyptus globulus Labill. (Thamarus et al. 2004). There are relatively few studies on MFA variation in loblolly pine, a widely planted tree in the southern United States and in other parts of the world. Myszewski et al. (2004) reported significant additive and dominant genetic effects for MFA in loblolly pine. Sewell et al. (2002) identified five quantitative trait loci (QTLs) affecting fibril angle in loblolly pine outbred families. The majority of these QTLs were verified by analyses of individual-ring traits.

MFA varies considerably within a tree. The angle can be as high as $50^{\circ}$ in the pith (center of the tree) and decreases rapidly towards the outer wood (Megraw 1985; Ying et al. 1994). Megraw (1999) reported a decreasing trend of MFA until ring 20 from the pith in 24 loblolly pine trees. The change in the angle is steepest until about ring 12 from the pith and then levels off thereafter (Jordan et al. 2005). Thus, it is important to fit an appropriate statistical model to partition variation to better predict breeding values of trees for selection. For example, some studies reported that nonlinear mixed models are better than standard nonlinear regression models for modeling within tree variation. Jordan et al. (2005) fitted a nonlinear mixed model to predict whole-tree MFA using ring number and sample height as predictors. A nonlinear (three-parameter) logistic model was also fitted to density data to predict wood density for a given growth ring and tree height (Daniels et al. 2002).

These early studies were generally based on small samples (e.g., Jordan et al. 2005) and did not partition genetic and environmental causes of variation in the trait. Some authors analyzed MFA of each ring separately as independent variables (e.g., Myszewski et al. 2004). In some cases, a group of ring values were averaged and linear models were fitted to each group. Typically, measurements taken on several rings from each tree are correlated. Thus, treating MFA as a "repeated measure" is logical. Analyzing repeated measures as independent variables may violate the linear model assumption of independence of errors (Apiolaza et al. 2000). Treating multiple measurement of the same trait over time as longitudinal data allows modeling the variation in heritability and genetic correlations with age (Apiolaza and Garrick 2000).

The objectives of this study were to $(i)$ use a linear mixed model to account for variation in MFA of young loblolly pine clones, (ii) partition the observed variance for MFA into its genetic and environmental components, (iii) compare the rate of change in MFA for different genotypes, and (iv) discuss the results in relation to genetic improvement of MFA in tree breeding programs.

\section{Materials and methods}

\section{Plant materials and measurements}

Using a factorial mating design, six unrelated parents of loblolly pine were mated to produce nine full-sib families. Full-sib progeny of nine crosses were hedged, resulting in five to nine clones per family. The first cycle of harvested cuttings (ramets) from hedges (clone) were rooted and then used to establish one experiment in Alabama in 1990. The subsequent cycles of harvested cuttings were rooted and used to establish a second experiment in Florida in 1991 (Frampton et al. 2000). At each location, randomized complete block design was used with six blocks per location. Each clone had two ramets planted side by side in each block, and each clone had 12 ramets planted at each location. A subset of this experiment was used for our analysis of MFA. Three blocks were selected at each location and all healthy, codominant trees of all clones in those blocks were marked in the winter of 2003. Using gas-powered drills, trees were drilled at breast height $(1.4 \mathrm{~m}$ above ground) from bark to bark. Wood increment cores $(12 \mathrm{~mm}$ diameter) were sampled from a total of 43 clones. The number of clones sampled per cross ranged from three to six. Each clone had three to six wood cores from each location and seven to 12 cores over two locations. The total numbers of trees sampled from the Alabama (AL) and Florida (FL) sites were 176 and 193, respectively.

Cellulose MFA was measured on each wood core using the SilviScan-2 tool, which uses X-ray diffraction and image analysis to measure a variety of wood properties (Evans and Ilic 2001). MFA was measured at $1 \mathrm{~mm}$ intervals on the wood cores from the pith to bark. Using the SilviScan Analyzer2001 program, average MFA for each ring was obtained. The number of rings for each tree (on a wood core) ranged from 9 to 13 depending on the growth of the tree. Ring width $(\mathrm{mm})$ and percent latewood were also obtained for each ring.

\section{Statistical analysis}

\section{Relationships of MFA with wood density and ring width}

Several graphs were produced to explore the relationships of MFA with wood density, ring width, and percent latewood before removing the tree effects (tree to tree variation). Plots of MFA versus ring number for each location (AL and FL) are given in Fig. 1. The scatterplot of wood density and MFA suggested a linear relationship between two variables measured at the ring level within each tree (Fig. 2a). These two variables were also averaged for each ring across all the trees measured in the experiment and were plotted against the ring number. Wood density and MFA showed opposite relationships with ring number (Fig. 2b). The scatterplot of ring width and MFA suggested a logarithmic relationship (Fig. 2c).

Since each tree has multiple measurements, i.e., one MFA value for each ring, the relationships of MFA with wood density and with ring width were studied after adjusting for the tree to tree variation (blocking on the tree). To adjust for the tree effect in the regression models, a random tree effect was included as an independent variable (a CLASS variable in the SAS GLM procedure) in fitting the linear and logarithmic regression models. The models were fitted with the GLM procedure of SAS (SAS Institute Inc. 1996). The SOLUTIONS option in the GLM procedure was used to obtain the intercept and regression coefficients (see Appendix A for the GLM code).

\section{Model building}

The response variable MFA is a repeated measure for each tree. There are up to 13 rings and $13 \mathrm{MFA}$ values for each tree. The trend of MFA from the pith (ring 1) to the 
Fig. 1. Spaghetti plots of cellulose MFA versus the growth rings from the center of trees (pith) to the bark at two locations. MFA decreases from the pith to the bark of trees. Except for some trees, rings 10 and 11 did not form in the trees of the FL site due to slower growth and also due to planting 1 year later than the AL site.

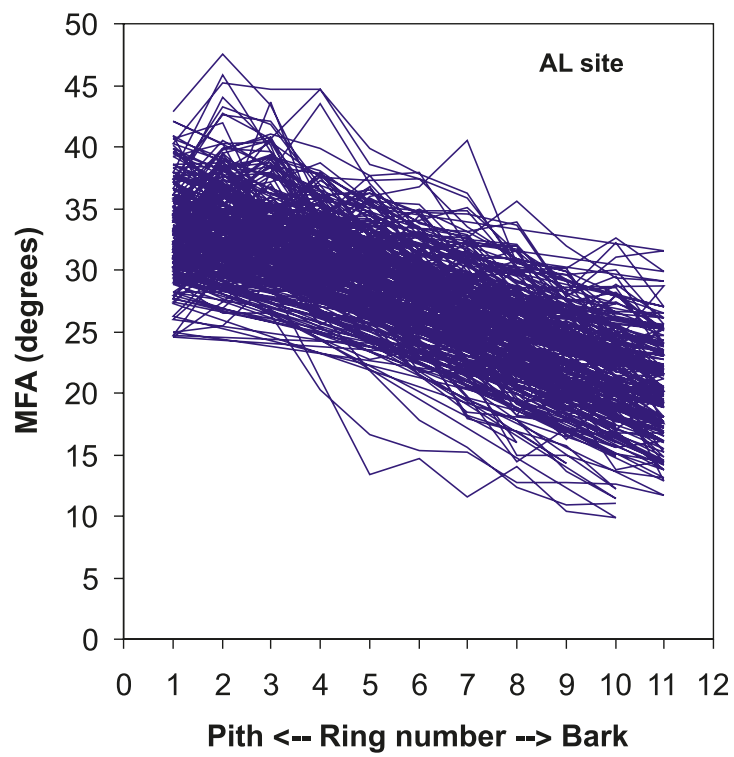

bark (ring 13) is not linear, although it is hard to see in the plots of MFA versus ring number (Fig. 1). Because ring number is a quantitative variable, the MFA was modeled as a second-order polynomial function of ring number. This gives smoothed trends over rings and yields equations that can be used for comparing crosses or clones at specific rings. Ring width decreases from the pith to the bark, whereas percent latewood increases. Ring width and percent latewood were used as covariates in the model to account for their effects on MFA variation. Family (cross) and clone are considered random effects, with clones nested within families. Site and block are considered fixed effects in this

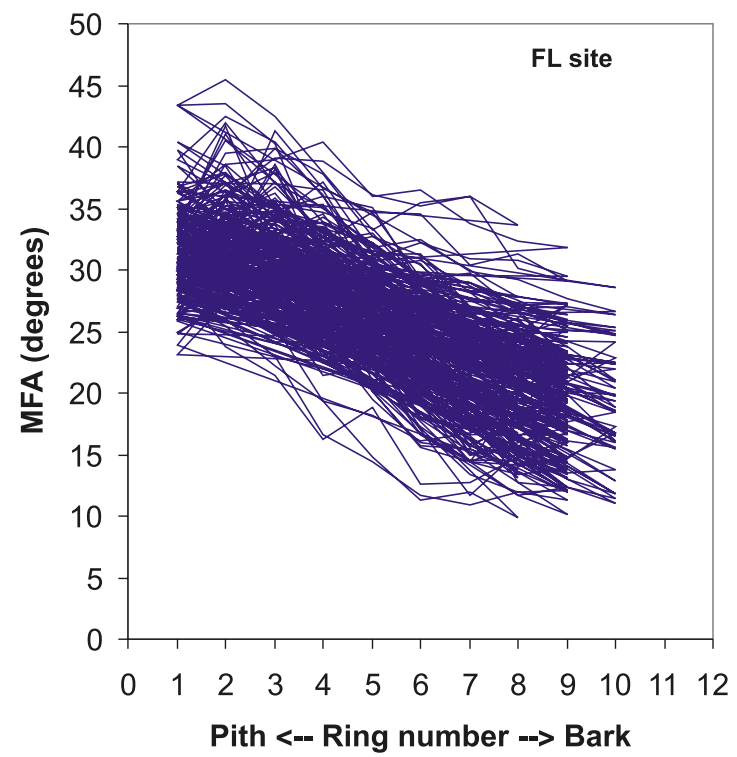

experiment, with blocks nested within sites. Block 1 in the AL site is different from block 1 in the FL site. The full second-order mixed model included terms for sites, blocks within sites, families, clones within families, tree within block, and clone, ring, ring width, and percent late wood. Because the block within site effect was not significant, and all variance components involving block effects were estimated to be zero, these terms were dropped from the second model. All other terms with variance components estimated to be zero were subsequently dropped from the final model. The final model is

$$
\begin{aligned}
{[1] \quad Y_{i j k l m}=} & \mu+\beta_{1} W_{i j k l m}+\beta_{2} W \times W_{i j k l m}+\beta_{3} L_{i j k l m}+\beta_{4} L \times L_{i j k l m}+\beta_{5} W_{i j k l m} L_{i j k l m}+S_{i}+F_{j} \\
& +C(F)_{k(j)} \\
& +(S \times C(F))_{i k(j)} \\
& +T(S F C)_{l(i j k)}+\beta_{6} R_{m}+\beta_{7} R \times R_{m} \\
& +\beta_{8 i}(S \times R)_{i m}+\beta_{9 i}(S \times R \times R)_{i m}+\beta_{10 j}(F \times R)_{j m}+\beta_{11 k(j)}(C \times R)_{k m(j)}+\epsilon_{i j k l m}
\end{aligned}
$$

where $Y_{i j k l m}$ is the response variable (MFA) of the $m$ th ring on the $l$ th tree of $k$ th clone in $j$ th family in the $i$ th site, $\mu$ is the overall mean, $W_{i j k l m}$ is the ring width centered to have zero mean, $L_{i j k l m}$ is the ring percent latewood centered to have zero mean, $S_{i}$ is the $i$ th site effect $(i=1,2), F_{j}$ is the $j$ th random family effect assumed normally and independently distributed, $\sim \operatorname{NID}\left(0, \sigma_{F}^{2}\right)(j=1$ to 9$), C(F)_{k(j)}$ is the $k$ th random clone effect nested within the $j$ th family, $\sim \mathrm{NID}\left(0, \sigma_{C(F)}^{2}\right)(k=1$ to 6$),(S \times C(F))_{i k(j)}$ is the random interaction of the $k$ th clone within the $j$ th family by $i$ th site, $\sim \operatorname{NID}\left(0, \sigma_{S C(F)}^{2}\right), T(S F C)_{l(i j k)}$ is the $l$ th random tree effect of the $k$ th clone within the $j$ th family in the $i$ th site, $\sim \mathrm{NID}(0$, $\left.\sigma_{T(S F C)}^{2}\right)(l=1$ to 6$), R_{m}$ is the $m$ th ring ( $m=1$ to 13 centered to have zero mean), and $\varepsilon_{i j k l m}$ is the residual withintree error, $\varepsilon_{i j k l m} \sim \mathrm{N}(0, \mathbf{R})$, where $\mathbf{R}$ is the covariance structure among measurements within a tree.
Note that $\beta_{8 i}$ indicates a modification to the linear ring coefficient for the $i$ th site; $\beta_{10 j}$ and $\beta_{11 k(j)}$ indicate random modifications to the linear ring coefficient for the $j$ th family and the $k$ th clone, with variance components $\sigma_{R F}^{2}$ and $\sigma_{R C(F)}^{2}$, respectively. The key features of this model are genetics effects, environmental effects, and the covariates: the family $(F)$ and clone $(C)$ terms are genetic and the site $(S)$, interaction terms of site, tree effect $(T)$, the interaction of ring by clone $(C \times R)$, family $(F \times R)$, and site $(S \times R)$ are environmental effects. Similarly, the residual $(\varepsilon)$ is due to measurement differences within tree and is environmental. Finally, linear, quadratic, and interaction terms of ring width $(W)$ and percent latewood $(L)$ are covariates.

Two central questions in the study are $(i)$ how does MFA change across rings and (ii) how do differences between clone means change across rings? Similar questions can be asked for 
Fig. 2. (a) Relationship between microfibril angle (MFA) and wood density across all of the trees (316) used in the study. Wood density is regressed on MFA. Data in this figure are on a ring basis before removing tree to tree variation. Wood density as a predictor variable explained $36 \%$ of the variation in MFA before removing the tree effect. When the tree to tree variation was removed, the predictor model $($ MFA $=-0.047$ density +51.6$)$ explained $72 \%$ of the variation. $(b)$ MFA and wood density from the center of the tree (pith) to the bark. Each data point is the ring average across 316 trees. In other words, MFA and wood density were averaged for each ring across all trees and plotted against ring number. The trend in MFA and in wood density within trees is in the opposite direction. (c) Relationship between MFA and ring width across all 316 trees. A logarithmic model is fitted to the data. Ring width alone explained $61 \%$ of the variation $\left(R^{2}=0.61\right)$ in MFA before removing tree to tree variation. However, the prediction model (MFA $=7.9 \ln$ (ring width) +7.3 ) using ring width as a predictor variable explained $84 \%$ of the variation after removing the tree to tree variation. (d) MFA and ring width for ring number from the pith of the tree (ring 1) to the bark (ring 11). Data points are averages across 316 trees.
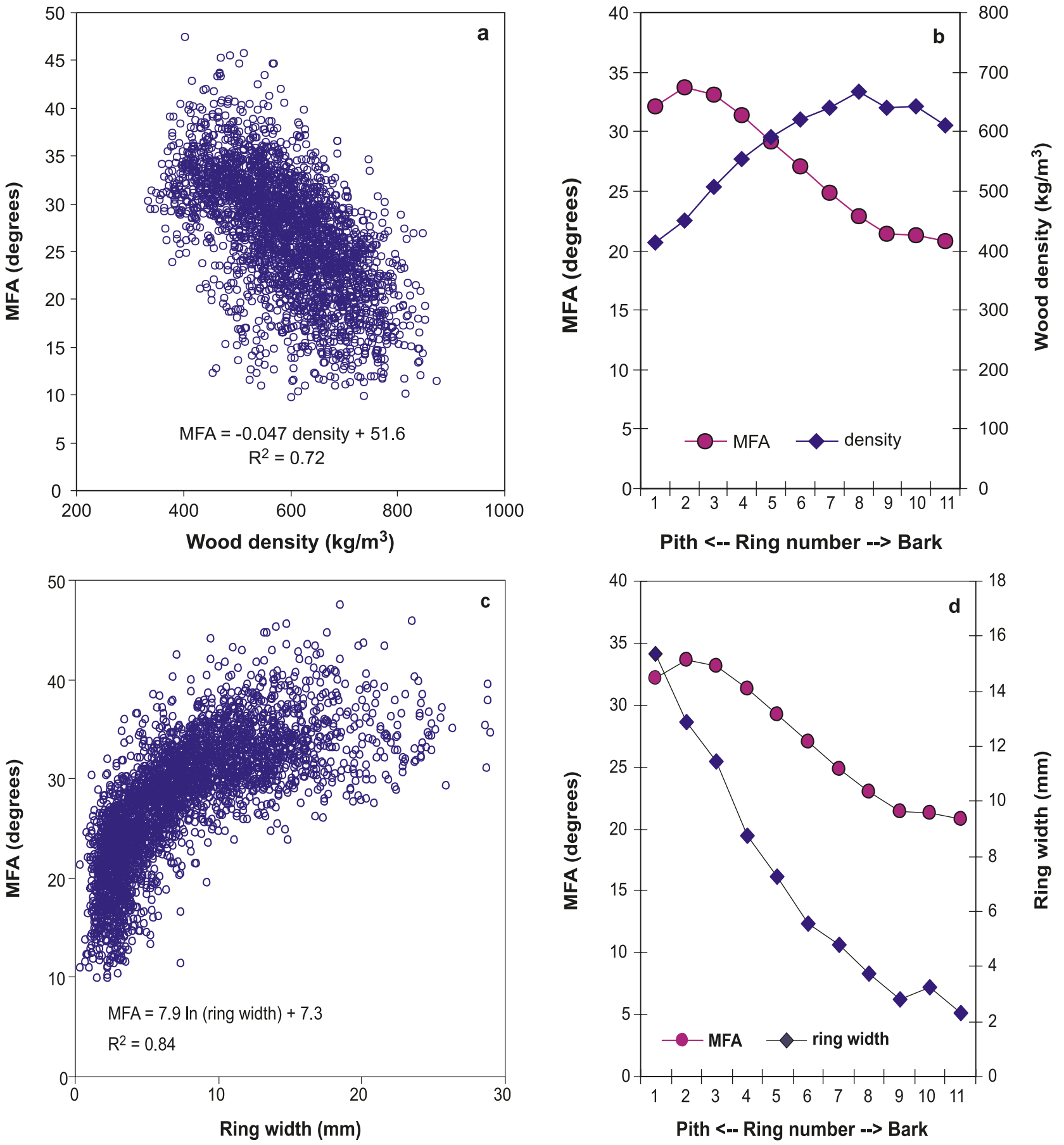
family effects. The first question can be answered by examining the coefficient for ring effects. The second question can be answered by examining how ring number affects the differences among clone means. A clone by ring interaction $\left(\sigma_{R C(F)}^{2}\right)$ indicates that the regression of MFA on ring number differs by clone. In another words, a significant interaction term indicates that the rate of decrease in MFA differs by clone. Some clones may produce narrower MFA at earlier ages than others.

The model given in eq. 1 can be written in matrix form:

$$
\text { [2] } \quad \boldsymbol{y}=\mathbf{X} \beta+\mathbf{Z} \gamma+\epsilon
$$

where $\boldsymbol{y}$ is the vector of observations, $\mathbf{X}$ is the incidence matrix of fixed effects, $\beta$ is the vector of fixed effects, $\mathbf{Z}$ is the incidence matrix of random effects, $\gamma$ is the vector of random effects, and $\varepsilon$ is the vector of residuals. One of the key assumptions of the mixed model is that the random effects and the residuals are normally distributed and independent of each other with the following expectations and covariance matrices:

$$
\text { [3] } E\left[\begin{array}{l}
\gamma \\
\epsilon
\end{array}\right]=\left[\begin{array}{l}
0 \\
0
\end{array}\right], \operatorname{Var}\left[\begin{array}{l}
\gamma \\
\epsilon
\end{array}\right]=\left[\begin{array}{cc}
\mathbf{G} & 0 \\
0 & \mathbf{R}
\end{array}\right]
$$

where the $\gamma$ vector contains the random effects and the $\varepsilon$ vector contains the residual errors. The variance-covariance matrix of observations is $\operatorname{Var}(\boldsymbol{y})=\mathbf{Z G} \mathbf{Z}^{T}+\mathbf{R}$ (Littell et al. 1996). The $\mathbf{G}$ accounts for genetic effects and the tree effects, while $\mathbf{R}$ accounts for random residual effects within a tree. We used a diagonal $\mathbf{G}$ matrix containing the variance components for the family effect, the clone (within family) effect, the site $\times$ clone(within family) interaction, the tree effect (within family clone and site), ring $\times$ family coefficients, and ring $\times$ clone (within family) coefficients, with off-diagonal elements equal to zero. Since families sharing the same parents are related, they are not actually independent. In a completely realistic model, the off-diagonal elements of $\mathbf{G}$ corresponding to the related families would be 0.5 of the additive genetic variance (genetic covariance between full-sibs), while the diagonal elements are the variance components of random effects. The $\mathbf{R}$ matrix specifies the covariance structure for errors within a tree. We assume that observations on the same tree are correlated; models for this correlation are discussed in the next section.

\section{Choice of covariance structure}

In this study, MFA measurements were taken on different growth rings within each tree. Note that the trees are often called "subjects" in the usual terminology for repeated measures data. It is reasonable to think every observation within a tree has a higher correlation with each other than those among different trees. Similarly, two measurements taken from two adjacent rings in a tree are expected to have a higher correlation than measurements taken from rings far apart.

To draw valid conclusions about the clone means, it is essential to use appropriate covariance structure for the model. Covariance structure affects the standard errors of estimates, especially when the data are not balanced and when there are missing values. It may also affect the generalized least squares estimates (Littell et al. 1998).

We examined several covariance structures including the general covariance (unstructured), compound symmetry (CS), autoregressive order 1 (AR1), banded Toeplitz with two bands (TOEP2), and spatial power or Markov (SP(POW)(c)) models. The AR1 covariance structure exploits the spatial relationships among the rings. Two measurements taken on two adjacent rings are expected to be correlated. As the measurements get farther apart, the correlations are expected to decrease exponentially. The CS structure specifies that all rings have the same variance for the MFA, and regardless of the distance between rings, all the pairs of the rings have the same covariances. This is similar to the covariance structure implied by a split-plot model (Littell et al. 1998). The Toeplitz covariance structure is a banded structure in which the two bands along the diagonal of the matrix have the same covariance. The covariance between the rings outside the band is zero. In addition, this structure assumes that the variance is equal for all of the rings. We used maximum likelihood in the SAS MIXED procedure to fit different correlation structures to the model (SAS Institute Inc. 1996). Model selection criteria AIC, BIC, and the log likelihood were used to determine the best correlation structure for the data. We used the AR1 covariance structure for prediction of clone means.

\section{Variance components and their functions}

Variance components were estimated for all the random factors in the model using restricted maximum likelihood. This method is the default in the SAS MIXED procedure and is considered more efficient than analysis of variance based methods and less biased than maximum likelihood. To have convergence when running the model, the PARMS option in the MIXED procedure was used with initial (starting) values.

The variance explained by the family term is due to genetic differences among full-sib families. Similarly, the variance component for clones within family is due to genetic differences among clones (Isik et al. 2003). Theoretically, the covariance among full-sib families can be partitioned into components attributable to additive $\left(\sigma_{\mathrm{A}}^{2}\right)$, dominance $\left(\sigma_{\mathrm{D}}^{2}\right)$ (interactions of genes in the same locus), and epistatic effects $\left(\sigma_{\mathrm{AA}}^{2}, \sigma_{\mathrm{AD}}^{2}, \sigma_{\mathrm{DD}}^{2}, \ldots\right)$ (interactions of genes in different loci) as follows:

$$
\sigma_{\mathrm{F}}^{2}=\frac{1}{2} \sigma_{\mathrm{A}}^{2}+\frac{1}{4} \sigma_{\mathrm{D}}^{2}+\frac{1}{4} \sigma_{\mathrm{AA}}^{2}+\frac{1}{8} \sigma_{\mathrm{AD}}^{2}+\frac{1}{16} \sigma_{\mathrm{DD}}^{2}+\ldots
$$

The remaining genetic variances are among clones within full-sib families:

$[5] \quad \sigma_{C(F)}^{2}=\frac{1}{2} \sigma_{\mathrm{A}}^{2}+\frac{3}{4} \sigma_{\mathrm{D}}^{2}+\frac{3}{4} \sigma_{\mathrm{AA}}^{2}+\frac{7}{8} \sigma_{\mathrm{AD}}^{2}+\frac{15}{16} \sigma_{\mathrm{DD}}^{2}+\ldots$

Assuming the epistatic genetic interactions are absent or negligible, the full-sib family variance component and clone within-family variance component can be expressed as a linear function of additive and dominance gene actions:

$$
\begin{aligned}
& \text { [6] } \sigma_{F}^{2}=\frac{1}{2} \sigma_{\mathrm{A}}^{2}+\frac{1}{4} \sigma_{\mathrm{D}}^{2} \\
& {[7] \quad \sigma_{C(F)}^{2}=\frac{1}{2} \sigma_{\mathrm{A}}^{2}+\frac{3}{4} \sigma_{\mathrm{D}}^{2}}
\end{aligned}
$$

In this kind of mating design, i.e., clones within a few fullsib families, tree breeders are often interested in selecting clones; therefore, broad-sense heritability or repeatability of 
clone means is of particular interest. Genetic gain predictions from selection of families and clones require calculation of phenotypic variances of family means and clone means. Traditionally, phenotypic variances of family means across all families are derived from variance components. For example, phenotypic variance of family means for this study would be the family variance component plus a fraction of variance components from all other random terms in the model as

$$
\begin{aligned}
\operatorname{Var}\left(\bar{Y}_{. j \ldots} \ldots\right)=\sigma_{F}^{2}+\sigma_{C(F)}^{2} / c+\sigma_{S C(F)}^{2} & / c s \\
& +\sigma_{T}^{2} / s f c+\sigma_{\epsilon}^{2} / s f c l
\end{aligned}
$$

where $\sigma_{F}^{2}, \sigma_{C(F)}^{2}, \sigma_{S C(F)}^{2}, \sigma_{T}^{2}$, and $\sigma_{\epsilon}^{2}$ are variance components for random effects in model $1 ; c, s, f$, and $l$ are the number of clones, sites, families, and trees, respectively. However, this derivation is based on the assumption of independently distributed errors and it does not take into account covariances in the model. In the above equation, the $\sigma_{\epsilon}^{2} / s f c l$ term is a problem. Using the linear mixed model given in eq. 1, the $j$ th full-sib family mean $\left(\bar{Y}_{. j} \ldots\right)$ is

$$
\begin{aligned}
& \text { [8] } \quad \bar{Y}_{. j \ldots}=\mu+\beta_{1} \bar{W} \ldots \ldots+\beta_{2} \overline{\mathrm{WW}} \ldots \ldots+\beta_{3} \bar{L} \ldots \ldots \\
& +\beta_{4} \overline{\mathrm{LL}} \ldots . .+\beta_{5} \overline{\mathrm{WL}} \ldots . .+\bar{S} .+F_{j} \\
& +\overline{\mathrm{C}(\mathrm{F})} \cdot{ }_{j} / c_{j}+\overline{\mathrm{SC}(\mathrm{F})} \cdot j \cdot / s c_{j} \\
& +\overline{\mathrm{T}(\mathrm{SCF})}_{\cdot j . .} . /\left(s \Sigma t_{j k}\right)+\beta_{6} \bar{R} \ldots . .+\beta_{7} \overline{\mathrm{RR}} \ldots . . \\
& +\bar{\beta}_{8} \cdot \bar{R} \ldots \ldots+\bar{\beta}_{9} \cdot \overline{\mathrm{RR}} \ldots \ldots+\beta_{10 j} \bar{R} \ldots \ldots \\
& +\bar{\beta}_{11 k(j)} \bar{R} \ldots . .+\bar{\epsilon}_{\cdot j \ldots} \ldots /\left(s \Sigma t_{j k}\right)
\end{aligned}
$$

where $s, c_{j}$, and $t_{j k}$ are the number of sites, clones, and trees per clone for the $j$ th full-sib family, respectively. Subscript $j$ is used because full-sib families had different numbers of clones and clones had different numbers of trees. The average ring mean $(\bar{R})$ and ring mean square $(\overline{\mathrm{RR}})$ are centered and the terms may be dropped from above equation. The $j$ th full-sib family mean $\left(\bar{Y}_{. j} \ldots\right)$ and the variance of the $j$ th full-sib family mean $\left(\operatorname{Var}\left(\bar{Y}_{. j} \ldots\right)\right)$ can be written more simply in matrix form:

$$
\text { [9] } \quad \bar{Y}_{. j \ldots}=\boldsymbol{l}_{1}^{\prime} \boldsymbol{\beta}+\boldsymbol{m}_{1}^{\prime}\left[\begin{array}{l}
\gamma \\
\epsilon
\end{array}\right]
$$

$$
\operatorname{Var}\left(\bar{Y}_{. j \ldots} \ldots\right)=\boldsymbol{m}_{1}^{\prime}\left[\begin{array}{cc}
\mathbf{G} & 0 \\
0 & \mathbf{R}
\end{array}\right] \boldsymbol{m}_{1}
$$

where $\boldsymbol{l}_{1}$ is the vector of coefficients for the fixed effects terms, $\boldsymbol{m}_{1}$ is the vector of coefficients for the random effect terms, $\mathbf{G}$ is the genetic matrix, and $\mathbf{R}$ is the error variance matrix as explained for eq. 2. Using linear combinations of fixed and random effects, individual clone means $\left(\bar{Y}_{\cdot j k . .}\right)$ are

$$
\begin{aligned}
& \bar{Y}_{. j k . .}=\mu+\beta_{1} \bar{W} \ldots .+\beta_{2} \overline{\mathrm{WW}} \ldots \ldots+\beta_{3} \bar{L} \ldots . . \\
& +\beta_{4} \overline{\mathrm{LL}} \ldots . .+\beta_{5} \overline{\mathrm{WL}}_{\ldots . .}+\bar{S} .+\bar{F}_{j}+\overline{\mathrm{C}}(\mathrm{F})_{j k} \\
& +\overline{\mathrm{SC}(\mathrm{F})} \cdot{ }_{j k} / s+\overline{\mathrm{T}(\mathrm{SCF})}_{\cdot j k} \cdot / s t_{j k}+\beta_{6} \bar{R} \ldots . . \\
& +\beta_{7} \overline{\mathrm{RR}} \ldots . .+\bar{\beta}_{8} \cdot \bar{R} \ldots . .+\bar{\beta}_{9} \cdot \overline{\mathrm{RR}} \ldots \ldots \\
& +\beta_{10 j} \bar{R} \ldots . .+\beta_{11 k(j)} \bar{R} \ldots . .+\bar{\epsilon}_{. j k} . . / s t_{j k}
\end{aligned}
$$

Clone means $\left(\bar{Y}_{\cdot j k . .}\right)$ and variance of clone means, $\operatorname{Var}\left(\bar{Y}_{. j k} ..\right)$ can be written in matrix form as

$$
\bar{Y}_{\cdot j k \cdot .}=\boldsymbol{l}_{2}^{\prime} \boldsymbol{\beta}+\boldsymbol{m}_{2}^{\prime}\left[\begin{array}{l}
\gamma \\
\epsilon
\end{array}\right]
$$

$$
\operatorname{Var}\left(\bar{Y}_{. j k . .}\right)=\boldsymbol{m}_{2}^{\prime}\left[\begin{array}{cc}
\mathbf{G} & 0 \\
0 & \mathbf{R}
\end{array}\right] \boldsymbol{m}_{2}
$$

where $\boldsymbol{l}_{2}^{\prime}$ and $\boldsymbol{m}_{2}^{\prime}$ are the vectors that contain the coefficients for computing $\bar{Y}_{\cdot j k .}$. The definitions of the terms were given before. The SUBJECT and $\mathrm{V}$ option in the MIXED procedure of SAS produce the estimated $\mathbf{V}$ matrix for the $j$ th family. Then, using SAS IML code, the variance of the family means and clone means were estimated based on eqs. 9-13 (see SAS codes in Appendices A and B). The variances of the nine full-sib family means varied slightly because families had different numbers of clones and different numbers of trees per clone. Variances of the nine full-sib families were averaged to obtain the phenotypic variance of full-sib family means (denominator in eq. 14). A similar approach was followed for clones, but due to a larger number of clones (43), the phenotypic variances of only a few clones were calculated and averaged to get an approximate phenotypic variance of clone means.

Repeatability of full-sib family means was estimated as the ratio of the family variance component $\left(\sigma_{F}^{2}\right)$ and the phenotypic variance of the full-sib family means $\left(\Sigma \operatorname{Var}\left(\bar{Y}_{. j} \ldots\right) / f\right)$ :

$$
H_{\bar{F}}^{2}=\frac{\sigma_{F}^{2}}{\sum \operatorname{Var}\left(\bar{Y}_{\cdot j \ldots}\right) / f}
$$

where $f$ is the number of families used to calculate the phenotypic variance of full-sib family means. Repeatability of clone means was estimated as the ratio of variance component due to clones $\left(\sigma_{C(F)}^{2}\right)$ and phenotypic variance

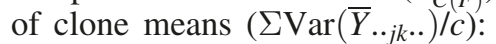

$$
H_{\bar{C}}^{2}=\frac{\sigma_{C(F)}^{2}}{\sum \operatorname{Var}\left(\bar{Y}_{. . j k . .}\right) / c}
$$

where $c$ is the number of clones used to calculate the average. Standard errors of repeatabilities were estimated using the Delta method and a simplified approximation to the phenotypic variance implemented with SAS IML code (see Appendix $\mathrm{B}$ for the formula and the program code). When the distribution of a ratio estimate is not known, such as the estimates in eqs. 14 and 15, then the Delta method is a way to approximate variances associated with the estimates (Lynch and Walsh 1998).

\section{Results and discussion}

\section{Relationships between MFA and wood density, ring width, and late wood percentages}

We found a linear relationship $\left(R^{2}=0.36\right)$ between wood density and cellulose MFA. As wood density increased from the pith to the outer wood, MFA decreased (Fig. 2a). Figure $2 a$ is based on individual ring values across 316 trees $(N=$ 3113 rings across all trees) before the tree to tree variation was removed. When tree to tree variation was removed using the CLASS statement in the GLM procedure of SAS (Appendix A), the relationship between wood density and MFA increased considerably $\left(R^{2}=0.72\right)$. The model root re- 
Table 1. Type 3 tests of fixed effects in the model using the AR1 error covariance structure.

\begin{tabular}{lllrr}
\hline Effect & $\begin{array}{l}\text { Numerator } \\
\text { df }\end{array}$ & $\begin{array}{l}\text { Denominator } \\
\text { df }\end{array}$ & \multicolumn{1}{c}{$\chi^{2}$} & $P>\chi^{2}$ \\
\hline Latewood\% (L) & 1 & 2746 & 81.2 & $<0.0001$ \\
$\mathrm{~L} \times \mathrm{L}$ & 1 & 2746 & 25.9 & $<0.0001$ \\
Ring width (W) & 1 & 2746 & 408.1 & $<0.0001$ \\
$\mathrm{~W} \times \mathrm{W}$ & 1 & 2746 & 139.1 & $<0.0001$ \\
$\mathrm{~L} \times \mathrm{W}$ & 1 & 2746 & 123.3 & $<0.0001$ \\
Site $(\mathrm{S})$ & 1 & 42 & 52.0 & $<0.0001$ \\
$\mathrm{Ring}(\mathrm{R})$ & 1 & 8 & 195.6 & $<0.0001$ \\
$\mathrm{R} \times \mathrm{R}$ & 1 & 8 & 172.5 & $<0.0001$ \\
$\mathrm{R} \times \mathrm{S}$ & 1 & 2746 & 7.7 & 0.0055 \\
$\mathrm{R} \times \mathrm{R} \times \mathrm{S}$ & 1 & 2746 & 15.9 & $<0.0001$ \\
\hline
\end{tabular}

Note: The blocks effect was not significant and was dropped from the final analysis. All of the terms in the model were significant at the $P<$ 0.05 level.

sidual mean square was 3.8. The intercept $\left(b_{0}=51.6\right)$ and the regression coefficient $\left(b_{1}=-0.047\right)$ were highly significant $(P<0.0001)$. When ring averages were calculated across all trees, wood density and MFA had almost opposite trends (Fig. 2b). Wood density increased from ring 1 (pith) to ring 8 and then decreased slightly. In contrast, MFA mostly decreased until ring 8 and then leveled off somewhat.

Ring width decreases from the pith of the tree to the outer wood but not in a linear fashion (Zobel and van Buijtenen 1989). To examine the relationships between ring width and MFA, we plotted MFA values of each ring against the ring width across all trees (Fig. 2c). MFA increased as the ring width increased. Using the ring width as explanatory variable, a logarithmic model of $\widehat{\mathrm{MFA}}=7.3+7.9 \ln$ (ring width) explained $84 \%$ of the variation in MFA.

Ring width and MFA were averaged for each ring across all 316 trees and plotted against ring number (Fig. 2d). Both MFA and ring width were larger near the pith and decreased toward the outside of the tree. The decrease in ring width was greater than the decrease in MFA from the pith to the outer wood. Surprisingly, the relationship between latewood percentage and MFA was weak (data not shown).

\section{Cellulose MFA variation in loblolly pine}

MFA varied significantly among sites $(P<0.0001$ level $)$ (Table 1). The fast-growing trees at the AL site had a larger MFA than did the slower growing trees at the FL site (Fig. 3). The difference in MFA between the two sites was not constant for each ring but decreased slightly from the pith to the center of trees and widened towards the outer wood (Fig. 3). The different sites had significantly different rates of change of MFA with ring number, as indicated by significant ring by site and ring square by site interaction terms (Table 1). The estimated MFA at the FL site was $29.7^{\circ}$ at the pith (ring 1) and dropped to $19.8^{\circ}$ at ring 10 (Fig. 3). Estimated MFA was higher at the AL site, decreasing from $32.9^{\circ}$ at the pith to $22.7^{\circ}$ at the outer wood (ring 11 ). The difference between the two sites is not entirely explained by the smaller ring width and higher wood density at the FL site (ring width: $P<0.0001$, density: $P<0.0001$ ).

MFA varied considerably within trees. On average, MFA
Fig. 3. Predicted MFA estimates for two locations from eq. 1 using the ESTIMATE statements in the SAS MIXED procedure (see Appendix A for the formula and program code). The estimates are averaged over families, clones at average ring width, and percent latewood. The fast-growing AL site had greater MFA (unfavorable) than the slower growing FL site across all rings.

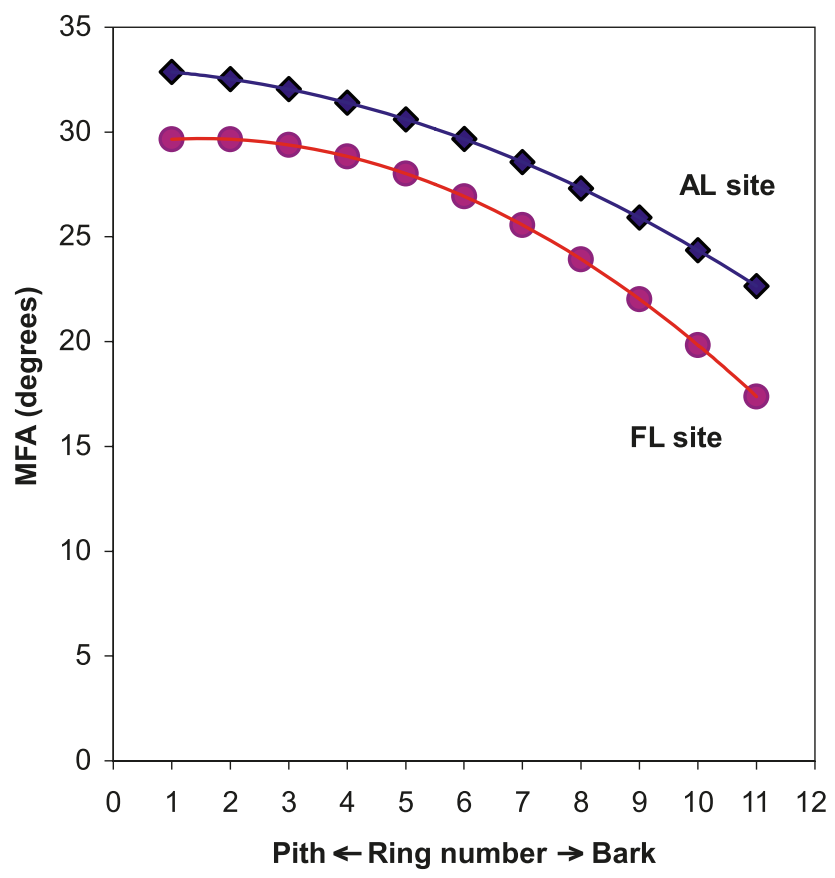

was $31.9^{\circ}$ at the core wood (ring 1 to ring 5) and dropped to $21.6^{\circ}$ at the outer wood (ring 8 to ring 11 ). Megraw et al. (1998) reported an average MFA of $35^{\circ}$ at the core wood (ring 1 to ring 5) and a range of 20 to $35^{\circ}$ at the outer wood (ring 6 to ring 20) of loblolly pine trees. The estimated MFA values in this study are smaller than those reported by Megraw et al. (1998). Sampling effects (i.e., different populations, ages, and genetic backgrounds) and measurement methods (SilviScan in this study versus X-ray diffraction used by Megraw et al. (1998)) may explain the difference in MFA values between the two studies. Myszewski et al. (2004) and Jordan et al. (2005) reported smaller MFA values for loblolly pine latewood than for earlywood. In mature trees of loblolly pine, MFA follows a decreasing trend in juvenile wood (first 5-7 rings from the pith) and then levels off at around ring 12 (Megraw et al. 1998) and does not change thereafter (Jones et al. 2005).

Several continuous variables were useful covariates for explaining variation in MFA. Percent latewood, the square of percent latewood, ring width, the square of ring width, and the interaction between percent latewood and ring width were all significantly related to MFA $(P<0.0001$ level $)$ (Table 1). The percentage of latewood increases until ring 5 (data not shown) and then reaches a plateau thereafter.

\section{Model selection and lack of fit}

Ring number and the quadratic ring (ring $\times$ ring) were good predictor variables of MFA (Table 1). Jordan et al. 
Table 2. Variance components ( \pm SE (approximate)) and percent variance explained by each random effect in the model.

\begin{tabular}{llc}
\hline Source & Estimate \pm SE & $\%$ of overall \\
\hline Family & $0.38 \pm 0.45$ & 2.9 \\
Clone (family) & $1.33 \pm 0.62$ & 10.0 \\
Site $\times$ clone $($ family) & $0.54 \pm 0.49$ & 4.1 \\
Ring $\times$ family & $0.03 \pm 0.02$ & 0.2 \\
Ring $\times$ clone $($ family) & $0.07 \pm 0.02$ & 0.5 \\
Tree $($ site $\times$ clone $\times$ family) & $3.40 \pm 0.66$ & 25.5 \\
Residual & $7.56 \pm 0.52$ & 56.9 \\
\hline
\end{tabular}

Note: The clone by ring interaction is essentially zero, suggesting that overall, there is not a great deal of variation in slopes among clones in the regression of MFA on ring number. In other words, the rate of decrease in MFA does not differ much for most clones.

(2005) reported that ring number and height (i.e., measurement along the tree stem) were significantly related to MFA in mature loblolly pine trees.

The residual explained a large proportion of the total variation in MFA (Table 2). To explore whether it might be caused by lack of fit, we further set up the model with the cubic term for ring number and all of its interactions with other terms. The results showed that the cubic ring effect and its interactions with other effects were all significant ( $\chi^{2}$ test, $\left.P<0.001\right)$. This indicates that a more complicated model would provide a better fit. The cubic model is not realistic but a nonlinear model such as a logistic model might describe the data better.

Models fitted to MFA reported in the literature varied depending on the age of the trees. Jordan et al. (2005) fitted a modified three-parameter logistic model to MFA measured on 21- to 24-year-old loblolly pine trees. The authors compared predicted curves of MFA for a single tree and found better prediction curves when random effects (ring by ring MFA values from increment wood cores taken from several trees) were included in the model. Myszewski et al. (2004) fitted a decreasing curvilinear model to MFA measured on 20- and 25-year-old trees.

The linear mixed model fitted to data in this study has certain advantages compared with nonlinear models. Fitting appropriate covariance structure and estimation of variance components is not straightforward when nonlinear or logistic models are used. Compared with nonlinear models, implementation of linear mixed models is straightforward with software such as the SAS MIXED procedure and allows us to use variance models with correlated errors to account for within-tree association (SAS Institute Inc. 1996).

\section{Covariance structure}

The fit statistics of different error covariance structures on the model are given in Table 3. Among the error covariance structures tested, AR1 was the best correlation structure for the within-tree errors as shown by the smaller AIC, BIC, and log likelihood model statistics (Table 3). The AR1 assumes that measurements taken from a tree are equally spaced (SAS Institute Inc. 1996). The average correlation decreases as the distance between measurements (rings) increases. The results showed that MFA values were correlated within a tree. The estimated correlation was 0.65 between two adjacent rings. A correlation matrix for a single tree is given in
Table 3. Different covariance structures for within-tree variation applied to the same mixed model and the model evaluation statistics.

\begin{tabular}{llll}
\hline & & & -2 log \\
Covariance structure & BIC & AIC & likelihood \\
\hline Compound symmetric (CS) & 14785.4 & 14784.2 & 14768.2 \\
Toeplitz with two bands (TOEP2) & 14262.0 & 14260.4 & 14244.4 \\
Markov SP(POW) & 14056.0 & 14054.4 & 14038.4 \\
Autoregressive order 1 (AR1) & 14056.0 & 14054.4 & 14038.4 \\
\hline
\end{tabular}

Note: The AR1 and Markov SP(POW) covariance structures were the best fit for the data.

Table 4. Phenotypic variances and repeatabilities of full-sib families and clone means with approximate standard errors.

\begin{tabular}{lll}
\hline & $\begin{array}{l}\text { Phenotypic } \\
\text { variance }\end{array}$ & Repeatability \pm SE \\
\hline Full-sib family means & 0.926 & $0.46 \pm 0.311$ \\
Clone means & 1.699 & $0.79 \pm 0.150$ \\
\hline
\end{tabular}

Appendix A. Although the Markov covariance structure had the same model statistics as AR1, the standard errors of linear combinations of effects could be greater when the Markov covariance structure is used (Littell et al. 1998). The unstructured covariance requires a large number of variances and covariances to be estimated from the data. This may lead to severe computational problems especially when there are missing values. In addition, this structure does not exploit the trends in variances and covariances across the rings and thus may cause erratic estimates of standard errors (Apiolaza et al. 2000; Apiolaza and Garrick 2000). We observed convergence problems when we used the unstructured covariance in SAS MIXED. The CS covariance structures and the TOEP2 covariance structure produced the highest model statistics and they were not suitable.

\section{Variance components}

Family differences and clone differences within-families explained about $2.9 \%$ and $10 \%$, respectively, of the overall MFA variation (Table 2). The percentage of variance explained by genetics $(12.9 \%)$ is considerable from the tree breeding point of view. A limited number of families resulted in imprecise prediction of the family variance component and does not merit speculation about family selection (Table 2). Clonal differences explained a large proportion of phenotypic variance for MFA. High repeatability of clone means (0.79) suggested that considerable improvement could be made for MFA if selection were based on clones. The repeatability estimates reported in the study are valid for the experimental population that we used and they could vary for different genetic samples or for different experiments. Myszewski et al. (2004) reported moderate to high individual tree narrow-sense heritabilities for MFA measured on different rings in loblolly pine. On average, the heritability estimate was around 0.35 and the range was 0.17 (earlywood of ring 4) to 0.51 (earlywood of ring 20) (Myszewski et al. 2004). These estimates may be biased upward due to genotype by environment interactions because the experiment was not replicated across different environments. 
The clone by site interaction variance component was moderate, accounting for $4.1 \%$ of overall variation. When deploying clones for solid wood products, selection of specific clones for specific sites may be desirable. However, the practical importance of the clone by site interaction of MFA needs to be further investigated before drawing any definite conclusions. In contrast with the significant clone by site interaction, the family by site interaction term was not significant and was dropped from the final model.

Tree to tree variation $(=$ tree $($ site $\times$ clone $\times$ family $))$ explained about $25.5 \%$ of the phenotypic variation. This must be due to environmental factors and measurement error because trees of a clone are genetically identical. Theoretically, the observed variance between copies of a clone is due to microenvironment. About $56.9 \%$ of overall variation in MFA was due to unexplained within-tree variation. The within-tree variance (residual) was greater than any other variance component explained by the random factors in the model. Residual variance is all of the unexplained variation that could not be accounted for by terms in the model. Jordan et al. (2005) also found greater variation within trees (along different heights of a stem) than among trees. Using a multivariate analysis approach, Apiolaza and Garrick (2000) analyzed wood density of Pinus radiata and they also reported greater within-tree variation.

\section{Rate of change for families and clones}

Variation in the linear ring effect on cellulose MFA across different families (ring by family interaction) was negligible (Table 2). Similarly, the linear ring by clone interaction explained less than $1 \%$ of the total phenotypic variance (Table 2), suggesting that MFA rates of change over rings did not vary across clones. The quadratic ring by clone interaction contributed less than $1 \%$ of the total variation and was omitted from the final model. Negligible or zero variances explained by interactions (ring by genotypes) suggested that the differences between clones or between families for MFA were stable from the pith to the outer wood. In other words, the rate of change from the pith to the outer wood was not different for different clones. When a clone had a higher MFA in the pith, the difference with other clones did not vary across the rings.

Predicted values of MFA for each ring for three randomly selected trees are given in Fig. 4. At the individual tree level, the observed interaction of ring by tree suggests considerable microenvironmental effects. Tree T19 had a wider MFA than trees T21 and T33 at early ages where the wood is juvenile. As the trees approached transition ages (ring 8 and beyond), the rank of the trees for MFA changed. Tree T21 had the narrowest angle beyond ring 6. From the tree improvement point of view, tree to tree variation for the rate of change does not have implications but family and clone level may have. If a clone reaches a narrower MFA at an early age than any other clone, then it would be preferred for selection to improve MFA in young pine plantations.

\section{Using MFA in tree breeding programs}

MFA, like wood density, appears to be under genetic control at the clone level. However, variance explained by family differences was small and associated with a large
Fig. 4. Observed MFA values (T33_ob, T19_ob, and T21_ob) and best linear unbiased predicted MFA values (T33-pr, T19-pr, and T21-pr) of three randomly selected trees at the AL site. Tree T33 produces narrower MFA at early ages than other trees. However, tree T21 reaches a narrower angle beyond ring 6 than the other two trees when the predicted lines are taken into account.

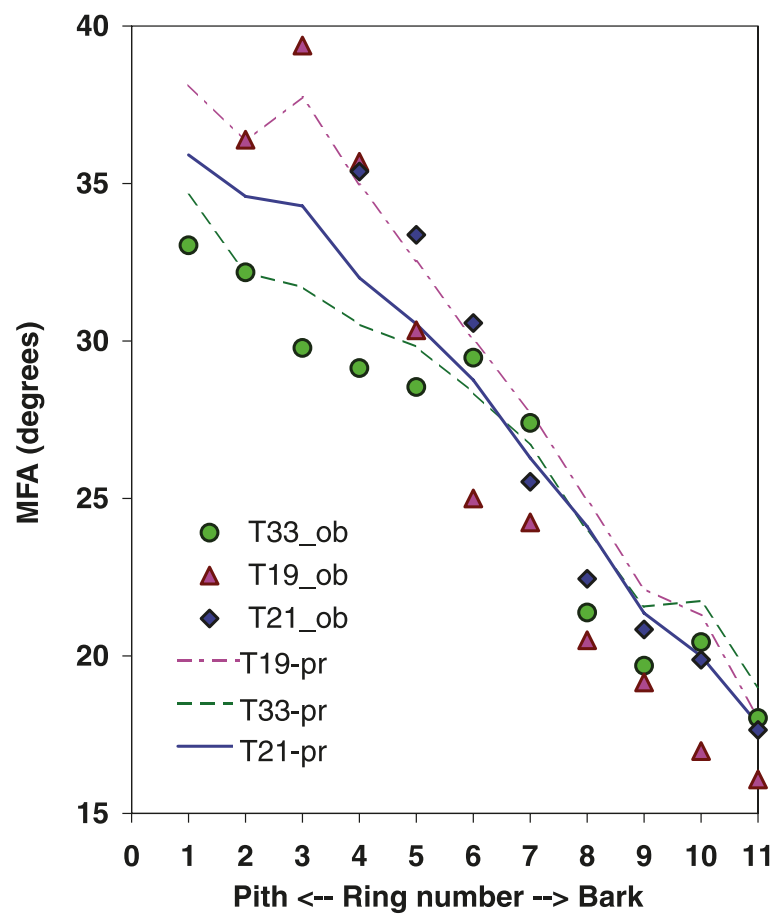

standard error. Further research on the relative contribution of additive and nonadditive genetic variation in MFA and the amount of genotype by environment interactions needs to be conducted to draw conclusions on the inheritance patterns of MFA. There are few studies of genetic variation in MFA in loblolly pine. Furthermore, the published results were based on limited sample sizes or based on experiments with no replication or no ability to estimate genetic control (i.e., Megraw et al. 1998; Myszewski et al. 2004; Jordan et al. 2005). Genetic correlations between MFA and growth, wood density, and stem straightness need to be studied because they would have a significant impact on selection strategies.

Compared with most studies, we studied a large sample of trees (316) with known genetic relatedness. Still, the limited number of families and clones per family used in this study did not allow us to draw conclusions about inheritance (narrow-sense heritability, causal genetic variances) of MFA. One drawback of this study is that the trees were relatively young. At the time of sampling, only the first 11 rings at the $\mathrm{AL}$ site and the first 10 rings at the FL site were available from the wood samples. In loblolly pine, the transition from juvenile to mature wood typically occurs at about age 11 (Zobel and van Buijtenen 1989). Thus, the curve of the MFA had not fully developed at the time of our sampling (Fig. 1). Older ages may be needed to see the full trend and to fit a curvilinear model as suggested by Jordan et al. (2005). However, for tree improvement programs, early evaluation is desirable and may be a necessity. Traditionally, genetic tests of loblolly pine are measured for 
growth at age 6 and for wood quality at ages 10-12. Evaluation of mature trees will lengthen the breeding cycles and reduce genetic gains per unit time.

Current methods for measuring MFA (such as X-ray diffraction and SilviScan) are prohibitively expensive to routinely use on large samples in tree improvement programs. Without further development of portable, cost-efficient methods, it will not be feasible to include MFA in tree improvement programs. Some recent studies suggested that it may be possible to use marker-aided selection to improve MFA in loblolly pine. Sewell et al. (2002) detected five QTLs for MFA in loblolly pine outbred families. The practical utilization of QTL in a marker-aided selection program requires verification in independent populations plus financial analysis (Dekkers and Hospital 2002). Further research is needed to test the consistency of QTLs affecting MFA in different families and their potential for use in a tree breeding program.

\section{Conclusions}

A linear mixed model was used to explain MFA variation in young loblolly pine trees. Quadratic ring effect was a good predictor of MFA. Latewood percentage and ring width were useful covariates to improve the model. Mixed models have advantages over nonlinear models for choosing the best residual variance-covariance structure. Among the covariance structures used, AR1 was the best for accounting for correlations among measurements across growth rings. Linear mixed models also allowed us to portion the observed variance into environmental and genetic components. MFA appeared to be under genetic control as suggested by high repeatability of clone means. Clones with low MFA could be selected for deployment in loblolly pine breeding programs. However, current MFA measurement methods (SilviScan and X-ray diffraction) are prohibitively expensive for large samples of trees. Development of cost-efficient measuring methods for large samples is critical to include MFA in tree breeding programs.

\section{Acknowledgements}

We thank Dr. Glenn T. Howe, Department of Forest Science, Oregon State University, for invaluable suggestions on this manuscript. We are grateful to the Associate Editor and two anonymous reviewers for critically reviewing the manuscript and making excellent suggestions to improve it. This study was funded by the members of the former North Carolina State University Project on Tissue Culture, the NCSU-Industry Cooperative Tree Improvement Program, the NCSU Loblolly and Slash Pine Rooted Cutting Program, and grants from the Department of Energy and USDA Initiative for Future Agriculture and Food Systems.

\section{References}

Apiolaza, L.A., Gilmour, A.R., and Garrick, D.J. 2000. Variance modelling of longitudinal height data from a Pinus radiata progeny test. Can. J. For. Res. 30: 645-654. doi:10.1139/cjfr-30-4645.

Apiolaza, L.A., and Garrick, D.J. 2000. Analysis of longitudinal data from progeny tests: some multivariate approaches. For. Sci. 47: 129-140.
Cave, I.D., and Walker, J.C.F. 1994. Stiffness of wood in fastgrown plantation softwoods. For. Prod. J. 44: 43-48.

Daniels, R.F., He, R., Clark, A., III, and Souter, R. 2002. Predicting wood properties of loblolly pine from stump to tip and pith to bark. In Proceedings of the Fourth Workshop. Connection between Forest Resources and Wood Quality: Modelling Approaches and Simulation Software, 8-14 September 2002, Harrison Hot Springs, B.C. Edited by G. Nepveu. IUFRO Working Party 55.01-04. INRI-Centre de Recherche de Nancy, France.

Dekkers, J.C.M., and Hospital, F. 2002. The use of molecular genetics in the improvement of agricultural populations. Nat. Rev. Genet. 3: 22-32.

Evans, R., and Ilic, J. 2001. Rapid prediction of wood stiffness from microfibril angle and density. For. Prod. J. 51: 53-57.

Entwistle, K.M., Eichhorn, S.J., and Navaranjan, N. 2005. The derivation of the cellulose microfibril angle by small-angle $\mathrm{X}$ ray scattering from structurally characterized softwood cellwall populations. J. Appl. Crystallogr. 38: 505-511.

Frampton, L.J., Jr., Li, B., and Goldfarb, B. 2000. Early field growth of loblolly pine rooted cuttings and seedlings. South. J. Appl. For. 24: 98-105.

Isik, F., Li, B., and Frampton, J. 2003. Additive, dominance and epistatic genetic variance estimates from a replicated clonal test of loblolly pine. For. Sci. 49: 77-88.

Jones, P.D., Schimleck, L.R., Peter, G.F., Daniels, R.F., and Clark, A., III. 2005. Nondestructive estimation of Pinus taeda L. wood properties for samples from a wide range of sites in Georgia. Can. J. For. Res. 35: 85-92. doi:10.1139/x04-160.

Jordan, L., Daniels, R.F., Clark, A., III, and He, R. 2005. Multilevel nonlinear mixed-effects models for the modeling of earlywood and latewood microfibril angle. For. Sci. 5: 357-371.

Kumar, S., Dungey, H.D., and Matheson, A.C. 2006. Genetic parameters and strategies for genetic improvement of stiffness in radiata pine. Silvae Genet. 55: 77-84.

Lichtenegger, H., Reiterer, A., Stanzl-Tscheqq, S.E., and Fratzl, P. 1999. Variation of cellulose microfibril angles in softwoods and hardwoods - apossible strategy of mechanical optimization. J. Struct. Biol. 128: 257-269. doi:10.1006/jsbi.1999. 4194. PMID:10633065.

Littell, R.C., Milliken, G.A., Stroup, W.W., and Wolfinger, R.D. (1996) SAS System for mixed models. SAS Institute Inc., Cary, N.C.

Littell, R.C., Henry, P.R., and Ammerman, C.B. 1998. Statistical analysis of repeated measures data using SAS procedures. J. Anim. Sci. 76: 1216-1231. PMID:9581947.

Lundgren, C. 2004. Microfibril angle and density patterns of fertilized and irrigated Norway spruce. Silva Fenn. 38: 107-117.

Lynch, M., and Walsh, B. 1998. Genetics and analysis of quantitative traits. Sinauer Associates, Inc., Sunderland, Mass.

Megraw, R.A. 1985. Wood quality factors in loblolly pine. The influence of tree age, position in tree, and cultural practice on wood specific gravity, fiber length, and fibril angle. TAPPI Press, Atlanta, Ga.

Megraw, R.A., Leaf, G., and Bremer, D. 1998. Longitudinal shrinkage and microfibril angle in loblolly pine. In Microfibril angle in wood. Edited by B.G. Butterfield. University of Canterbury Press, Christchurch, New Zealand. pp. 27-61.

Megraw, R.A., Bremer, D., Leaf, G., and Roers, J. 1999. Stiffness in loblolly pine as a function of ring position and height, and its relationship to microfibril angle and specific gravity. In Proceedings of the Third Workshop-Connection between Silviculture and Wood Quality through Modeling Approaches. IUFRO Working 
Party S5.01-04, La Londe-les Maures, France. IUFRO, Vienna, Austria. pp. 385-386.

Myszewski, J.H., Bridgwater, E.F., Lowe, J.W., Byram, T.D., and Megraw, A.R. 2004. Genetic variation in the microfibril angle of loblolly pine from two test sites. South. J. For. Res. 28: 196204.

SAS Institute Inc. 1996. SAS/STAT Software: changes and enhancements (through release 6.11). SAS Institute Inc., Cary, N.C.

Sewell, M.M., Davis, M.F., Tuskan, G.A., Wheeler, N.C., Elam, C.C., Bassoni, D.L., and Neale, D.B. 2002. Identification of QTLs influencing wood property traits in loblolly pine (Pinus taeda L.). II. Theor. Appl. Genet. 104: 214-222. doi:10.1007/ s001220051607.

Thamarus, K., Groom, K., Bradley, B., Raymond, C.A., Schimleck, L.R., Williams, E.R., and Moran, G.F. 2004. Identification of quantitative trait loci for wood and fibre properties in two full- sib pedigrees of Eucalyptus globulus. Theor. Appl. Genet. 109: 856-864. doi:10.1007/s00122-004-1699-4. PMID:15133606.

Uprichard, J.M., Kimberly, M.O., Foster, R.S., and Shelbourne, C.J.A. 1994. Thermomechanical pulping studied on the radiata pine clones: the effects of wood quality on paper making properties. Pan Pacific Conference, 6-9 November 1994, San Diego, Calif. TAPPI Press, Atlanta, Ga. pp. 83-99. ISBN 0-89852-931$\mathrm{X}$.

Ying, L., Kretschmann, D., and Bendtsen, E. 1994. Longitudinal shrinkage in fast-grown loblolly pine plantation wood. For. Prod. J. 44: 58-62.

Zobel, B.J., and van Buijtenen, J.P. 1989. Wood variation its causes and control. Springer Series in wood science. SpringerVerlag, New York.

\section{Appendix A}

Linear equations of individual ring estimates for two sites Estimate of ring $n$ value for the Alabama (AL) site:

$$
\widehat{Y}_{\mathrm{AL}}=\widehat{\mu}+\widehat{S}_{\mathrm{AL}}+\widehat{\beta}_{6} R_{n}+\widehat{\beta}_{7} R_{n}^{2}+\widehat{\beta}_{8, \mathrm{AL}} R_{n}+\widehat{\beta}_{9, \mathrm{AL}} R_{n}^{2}
$$

Estimate of ring $n$ value for the Florida (FL) site:

$$
\widehat{Y}_{\mathrm{FL}}=\widehat{\mu}+\widehat{S}_{\mathrm{FL}}+\widehat{\beta}_{6} R_{n}+\widehat{\beta}_{7} R_{n}^{2}+\widehat{\beta}_{8, \mathrm{FL}} R_{n}+\widehat{\beta}_{9, \mathrm{FL}} R_{n}^{2}
$$

\section{Regressing the MFA on wood density across 316 trees}

When fitting the regression model, the tree to tree variation was removed using the CLASS statement in the GLM procedure. A similar code was used to regress ring width on MFA using a logarithmic model.

ods html;

ods graphics on;

ods html path = 'C: \RESEARCH\Wood \SilviScan'"

gpath = 'C: $\backslash$ RESEARCH\Wood $\backslash$ SilviScan'"

file = 'GLM.htm'" ;

PROC GLM DATA = ring;

CLASS tree;

MODEL mfa = tree density / solution;

random tree;

output out $=$ new $\mathrm{p}=$ yhat $r=$ resid stdr $=$ eresid;

run; quit;

ods graphics off;

ods html close;

SAS MIXED procedure code used to run the model given in eq. 1

PROC MIXED DATA=ring COVTEST METHOD=REML ASYCOV NOCLPRINT=3;

CLASS site cross clone tree measure;

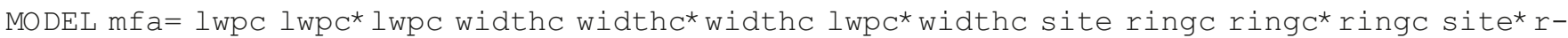
ingc site* ring ${ }^{\star}$ ringc/SOLUTION OUTP=pred CHISQ COVB;

RANDOM int clone site* clone ringc ringc* clone tree (site* clone) / SOLUTION SUBJECT=Cross V=1; REPEATED measure/TYPE=AR (1) SUBJECT=tree (site* cross* clone) RCORR;

PARMS $(0.38)(1.33)(0.54)(0.03)(0.066)(3.40)(0.65)(7.56) ;$

/* Estimation of MFA for rings at each site. The First 3 rings at each site were given here * /

/* AL site*/

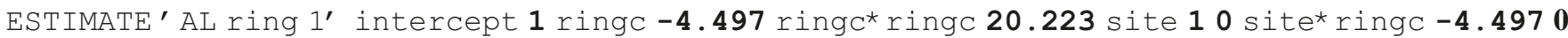
site*ringc*ringc 20.2230 ; 
ESTIMATE' AL ring 2' intercept 1 ringc $\mathbf{- 3 . 4 9 7}$ ringC ringc $\mathbf{1 2 . 2 2 9}$ site 10 site* ringc $\mathbf{- 3 . 4 9 7 0}$ site* ring * ringc 12.2290 ;

ESTIMATE' AL ring 3' intercept 1 ringc $\mathbf{- 2 . 4 9 7}$ ringc*ringc 6.235 site 10 site* ringc $\mathbf{- 2 . 4 9 7 0}$ site* ring $c^{\star}$ ringc 6.2350 ;

/* FL site*/

ESTIMATE' FL ring $1^{\prime}$ intercept 1 ringc $\mathbf{- 4 . 4 9 7}$ ringc* ringc 20.223 site 01 site* ringc 0 -4.497 site* ring $c^{\star}$ ringc 020.223 ;

ESTIMATE' FL ring 2' intercept 1 ringc -3.497 ringc*ringc 12.229 site 01 site* ringc $0-3.497$ site* ring c*ingc 012.229 ;

ESTIMATE' FL ring 3' intercept 1 ringc $\mathbf{- 2 . 4 9 7}$ ringc* ringc 6.235 site 01 site* ringc 0 -2.497 site*ringc*ringc 0 6.235;

ODS LISTING EXCLUDE V SOLUTIONF SOLUTIONR COVB ASYCOV;

ODS HTML EXCLUDE V SOLUTIONF SOLUTIONR COVB ASYCOV;

ODS OUTPUT SOLUTIONF=s_f SOLUTIONR=s_r COVPARMS=_varcomp ASYCOV=_COV COVB=_cOvb V=yvar; RUN;

/* Calculation of variance of family 1 mean * /

data yvar2; set yvar;

drop row index;

run;

PROC IML;

USE yvar2;

READ all into yvar2;

$\mathrm{L}=j(\mathbf{1}, \mathrm{NROW}($ yvar2 $), 1)$;

$\operatorname{SUMR}=\mathrm{L}[1,+] ;$ * Sum of row 1 ;

$\mathrm{L}=\mathrm{L} / \mathrm{SUMR}$;

varfamilymean $=L^{\star}$ yvar2* $L^{\prime}$;

PRINT varfamilymean;

RUN; QUIT;

Error $(\mathbf{R})$ within-tree covariance matrix for one tree

Table A1. Estimated $\mathbf{R}$ matrix for tree(site $\times$ cross $\times$ clone) A104207B AL 2142 .

\begin{tabular}{ccccccccccc}
\hline Row & Col1 & Col2 & Col3 & Col4 & Col5 & Col6 & Col7 & Col8 & Col9 & Col10 \\
\hline 1 & 1.00 & 0.65 & 0.42 & 0.28 & 0.18 & 0.12 & 0.08 & 0.05 & 0.03 & 0.02 \\
2 & 0.65 & 1.00 & 0.65 & 0.42 & 0.28 & 0.18 & 0.12 & 0.08 & 0.05 & 0.03 \\
3 & 0.42 & 0.65 & 1.00 & 0.65 & 0.42 & 0.28 & 0.18 & 0.12 & 0.08 & 0.05 \\
4 & 0.28 & 0.42 & 0.65 & 1.00 & 0.65 & 0.42 & 0.28 & 0.18 & 0.12 & 0.08 \\
5 & 0.18 & 0.28 & 0.42 & 0.65 & 1.00 & 0.65 & 0.42 & 0.28 & 0.18 & 0.12 \\
6 & 0.12 & 0.18 & 0.28 & 0.42 & 0.65 & 1.00 & 0.65 & 0.42 & 0.28 & 0.18 \\
7 & 0.08 & 0.12 & 0.18 & 0.28 & 0.42 & 0.65 & 1.00 & 0.65 & 0.42 & 0.28 \\
8 & 0.05 & 0.08 & 0.12 & 0.18 & 0.28 & 0.42 & 0.65 & 1.00 & 0.65 & 0.42 \\
9 & 0.03 & 0.05 & 0.08 & 0.12 & 0.18 & 0.28 & 0.42 & 0.65 & 1.00 & 0.65 \\
10 & 0.02 & 0.03 & 0.05 & 0.08 & 0.12 & 0.18 & 0.28 & 0.42 & 0.65 & 1.00 \\
\hline
\end{tabular}

Note: As seen in row 1, covariance decreases from the first measurement to the last.

\section{Appendix B. Variances of repeatabilities of family means and clone means estimates using the Delta method}

General formula for a ratio $(x / y)$

$$
\operatorname{Var}(x / y) \approx[E(x) / E(y)]^{2}\left[\operatorname{Var}(x) / E(x)^{2}+\operatorname{Var}(y) / E(y)^{2}-2 \operatorname{Cov}(x, y) / E(x) E(y)\right]
$$


Variance of repeatability of family means

$$
\operatorname{Var}\left(\frac{\widehat{\sigma}_{F}^{2}}{\sum \widehat{\operatorname{Var}}\left(\bar{Y}_{\cdot j \ldots) / f}\right.}\right)
$$

Let the phenotypic variance of family means be

$$
\sum \operatorname{Var}\left(\bar{Y}_{\cdot j \ldots)}\right) / f=\sigma_{P . F M}^{2}
$$

Then, approximate variance of repeatability of family means is

$$
\operatorname{Var}\left(H_{\bar{F}}^{2}\right)=\operatorname{Var}\left(\frac{\widehat{\sigma}_{F}^{2}}{\sum \widehat{\operatorname{Var}}(\bar{Y} . j \ldots) / f}\right) \approx\left(\frac{\sigma_{F}^{2}}{\sigma_{P . F M}^{2}}\right)^{2}\left[\frac{\operatorname{Var}\left(\widehat{\sigma}_{F}^{2}\right)}{\left(\sigma_{F}^{2}\right)^{2}}+\frac{\operatorname{Var}\left(\widehat{\sigma}_{P . F M}^{2}\right)}{\left(\sigma_{P . F M}^{2}\right)^{2}}-\frac{2 \operatorname{Cov}\left(\widehat{\sigma}_{F}^{2}, \widehat{\sigma}_{P . F M}^{2}\right)}{\left(\sigma_{F}^{2}\right),\left(\sigma_{P . F M}^{2}\right)}\right]
$$

Variance of repeatability of clone means

$$
\operatorname{Var}\left(\frac{\widehat{\sigma}_{C(F)}^{2}}{\sum \widehat{\operatorname{Var}}\left(\bar{Y}_{\cdot j k . .}\right) / c}\right)
$$

Let the phenotypic variance of clone means be

$$
\sum \operatorname{Var}\left(\bar{Y}_{\cdot j k . .}\right) / c=\sigma_{P . C M}^{2}
$$

Then, approximate variance of repeatability of clone means is

$$
\operatorname{Var}\left(H_{\bar{C}}^{2}\right)=\operatorname{Var}\left(\frac{\widehat{\sigma}_{C(F)}^{2}}{\sum \widehat{\operatorname{Var}}(\bar{Y} . j k . .) / c}\right) \approx\left(\frac{\sigma_{C(F)}^{2}}{\sigma_{P . C M}^{2}}\right)^{2}\left[\frac{\operatorname{Var}\left(\widehat{\sigma}_{C(F)}^{2}\right)}{\left(\sigma_{C(F)}^{2}\right)^{2}}+\frac{\operatorname{Var}\left(\widehat{\sigma}_{P . C M}^{2}\right)}{\left(\sigma_{P . C M}^{2}\right)^{2}}-\frac{2 \operatorname{Cov}\left(\widehat{\sigma}_{C(F)}^{2}, \widehat{\sigma}_{P . C M}^{2}\right)}{\left(\sigma_{C(F)}^{2}\right)\left(\sigma_{P . C M}^{2}\right)}\right]
$$

\section{SAS/IML code to estimate standard error of repeatability of family means using the Delta method}

The following IML code was modified for the variance of repeatability of clone means.

/* Variance of family repeatability */

PROC IML;

/* Read variance components matrix */

use_varcomp;

read all var Estimate\} into VC;

close_varcomp;

rown $=\{$ Fam Cf SCf rf RCf T_SFC arl eps $\}$;

$\operatorname{coln}=\{$ Estimates $\}$;

/* Read covariance matrix */

use _cov;

read all var \{ CovP1 CovP2 CovP3 CovP4 CovP5 CovP6 CovP7 CovP8\} into Cov;

close_cov;

/* \# of sites $\mathrm{S}=2$,

\# of Clones $\mathrm{C}=4.8$ per family,

\# of Family $\mathrm{F}=9$,

\# of Trees $\mathrm{T}=3.7$ per family per site, ( $\mathrm{T}=316 \mathrm{in}$ total/S/F/C) */

$\mathrm{s}=\mathbf{2} ; \mathrm{c}=\mathbf{4} .8 ; \mathrm{t}=\mathbf{3} .7 ; \mathrm{r}=9.9$;

/* Create Design matrix and Assign coeff. for Family * /

$\mathrm{AU}=\operatorname{shape}(0, \operatorname{nrow}(\mathrm{VC}), 1)$;

$\mathrm{AU}[\mathbf{1}, \mathbf{1}]=1 * 1 ; *<-$ assign coefficient for family variance;

$\mathrm{AV}=\operatorname{shape}(\mathbf{1}, \operatorname{nrow}(\mathrm{VC}), \mathbf{1})$;

$\operatorname{AV}[1,1]=1 ; *<-a s s i g n$ coeff for $\mathrm{FAM}=(1)$;

$\operatorname{AV}[2,1]=1 / C ; *<-a s s i g n$ coeff for $\operatorname{CLONE}=43 / 9=(4.8)$;

$\operatorname{AV}[3,1]=1 / \mathrm{s} / \mathrm{c} ; *<-$ assign coeff for $\operatorname{SITE}-\mathrm{CLONE}=(2 * 4.8)$;

$\operatorname{AV}[4,1]=0 ; *<-a s s i g n$ coeff for $\operatorname{RING}=(2 * 4.8 * 3.7 * 9.9)$; 
$\operatorname{AV}[5,1]=0 ; *<-$ assign coeff for RING-CLONE $=(2 * 4.8 * 3.7 * 9.9)$;

$\operatorname{AV}[6,1]=1 / \mathrm{s} / \mathrm{c} / \mathrm{t} ; *<-\operatorname{assign} \operatorname{coeff}$ for $\operatorname{TREE}=(2 * 4.8 * 3.7)$;

$\operatorname{AV}[\mathbf{7}, \mathbf{1}]=0 ; *<-\mathrm{AR} 1$ correlation;

$\mathrm{AV}[\mathbf{8}, \mathbf{1}]=\mathbf{1} / \mathrm{s} / \mathrm{c} / \mathrm{t} / \mathrm{r} ; *<-\operatorname{assign}$ coeff for Epsilon=(2*4.8*3.7*9.9);

$\mathrm{rho}=\mathrm{vC}[7]$;

sigsqeps $=\mathrm{vC}[8]$;

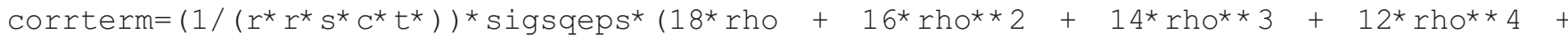
$10 *$ rho** $\left.5+8 * r h o * * 6+6^{*} r h o^{*} * 7+4 * r h o * * 8+2 * r h o * * 9\right)$;

Phen_f $=\mathrm{AV}$ * $* \mathrm{VC}+$ corrterm; *<-phenotypic variance of family means;

$\mathrm{H} 2 \mathrm{f}=\mathrm{AU} \cdot * \mathrm{VC} /(\mathrm{AV} \backslash * \mathrm{VC}) ; *<-$ Repeatability;

$\mathrm{fvC}=\mathrm{au}{ }^{\prime *} \mathrm{VC}$;

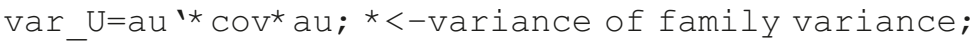

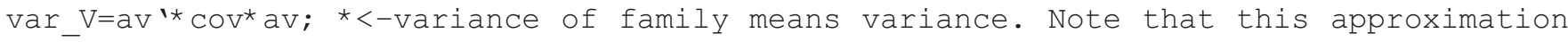
ignores within-tree correlations;

cov UV=au'* $\mathrm{COV}^{\star} \mathrm{av} ; *<-$ covariance;

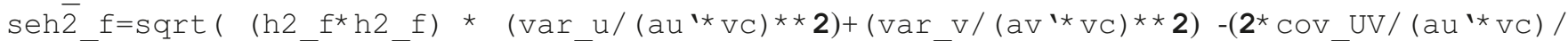
$\left.\left.\left.\left(\mathrm{av}{ }^{\prime *} \mathrm{vC}\right)\right)\right)\right)$

print

AV H2_f[ format=6.2] fvc[ format=6.2] Phen_f[ format=6.3] seH2 f[ format=6.3] ;

run; quit; 